\title{
Yagé: Crisis de occidente y trabajo espiritual
}

\author{
Yagé: Western crisis and spiritual work \\ Javier Ávila-Carbajal ${ }^{*}$ orcid.org/0000-0001-6457-2874 \\ Mariana Pedroza² orcid.org/0000-0002-9650-1218 \\ Oscar Angulo 3 orcid.org/0000-0001-6072-0382
}

1 Transdisciplina, Centro de Investigación y Estudios Avanzados, Cinvestav. Investigación en epistemología del conocimiento y terapéuticas. Ciudad de México, México.

2 Filosofía, Universidad Iberoamericana, UIA. Ciudad de México, México.

3 Sociología, Universidad Nacional Autónoma de México, UNAM. Investigación en los impactos socio-políticos de la guerra contra el narcotráfico en México y Colombia. Ciudad de México, México.

\section{Resumen}

Introducción: Ante la crisis epistemológica y sistémica que se encuentra en la civilización occidental, el yagé emerge como alternativa que invita a una reponderación axiológica profunda. Asimismo, el ritual del yagé evidencia los límites del conocimiento médico moderno, dando pauta al abordaje transdisciplinario. Por otro lado, se presentan consecuencias de inserción en el libre mercado, implicando problemas de lucro a costa de tradiciones originarias. En este contexto, se explora el concepto «trabajo espiritual» como práctica que busca descolocarse del colonialismo mercantil al tiempo que se aleja del modelo médico moderno. Objetivo: Reflexionar la incorporación del ritual de yagé en Occidente y sus posibilidades como alternativa epistemológica y médica. Materiales y métodos: Revisión de artículos de la base de datos especializados Web of Science, con la palabra clave: "ayahuasca". Resultados: Se estructuró la información teniendo en cuenta los aspectos relacionados con: (a) el contexto de incorporación del yagé al occidente, (b) los límites del conocimiento médico moderno y (c) los problemas de inserción al libre mercado. Conclusiones: Se apoya el diagnóstico de la ruptura epistemológica con occidente, pero reconociendo el estado inicial de las investigaciones y la falta de evidencias documentadas para entrar en una etapa más fructífera para el debate.

Palabras clave: Ayahuasca; mundo occidental; conocimiento; salud mental; terapias espirituales. (Fuente: DeCS, Bireme).

\begin{abstract}
Introduction: In the face of epistemological and systemic crisis in Western civilization, yagé emerges as an alternative that invites a deep axiological reponderation. The yagé ritual demonstrates the limits of modern medical knowledge, giving guidance to a transdisciplinary approach. On the other hand, there are consequences of insertion into the free market, involving profit problems at the expense of original traditions. Thus, the concept of "spiritual work" is explored as a practice that seeks to dislodge itself from commercial colonialism while moving away from the modern medical model. Objective: To reflect on the incorporation of the yage ritual in the West and its possibilities as an epistemological and medical alternative. Materials and methods: Review of articles from the specialized Web of Science database, with the keyword: "ayahuasca". Results: The information was structured considering aspects related to: (a) the context of incorporation of yagé into the West, (b) the limits of modern medical knowledge and (c) the problems of insertion into the free market. Conclusions: The diagnosis of the epistemological rupture with the West is supported while recognizing the initial state of the investigations and the lack of documented evidence in order to enter into a more fruitful debate.
\end{abstract}

Key words: Ayahuasca; western world; knowledge; mental health; spiritual therapies. (Source: DeCS, Bireme).

*Autor de correspondencia 


\section{Introducción}

El mundo occidental experimenta una crisis como civilización que ha llevado a buscar nuevos paradigmas que planteen alternativas de sanación y restitución de las relaciones del ser humano con la naturaleza y con su entorno. Esta crisis civilizatoria, se manifiesta en el deterioro ambiental, la pobreza relacional, así como en los malestares corporales y existenciales de los individuos(1). Esto trae como consecuencia la ruptura de paradigmas epistemológicos que hasta hace relativamente poco se consideraban incuestionables.

La impronta del yagé -o ayahuasca- en Occidente tiene lugar en medio de esta crisis. Valiéndose de un contexto de globalización que permite a la población buscar alternativas ajenas a su contexto inmediato, el yagé abre un campo de exploración de un paradigma completamente distinto al de la medicina moderna -e históricamente deslegitimado por ésta- propiciando con ello un desanclaje del tiempo y espacio moderno, y convirtiéndose así, por metonimia, en un referente alternativo a la crisis occidental(2).

La propagación del yagé en comunidades occidentales pone en evidencia los límites de la ciencia moderna y la necesidad apremiante de una pauta de comprensión transdisciplinar que aborde la complejidad del saber chamánico y las propiedades etnomedicinales del yagé desde un lugar bio-psicoantropo-social(3). Esto da lugar a nuevos planteamientos ontológicos que ponen en cuestión la soberanía de la epistemología moderna y evidencian límites en su saber(4). De este modo, la investigación del yagé brinda la posibilidad de un nuevo diálogo transdisciplinario entre diferentes campos para desde ahí repensar las nociones preconcebidas sobre la medicina, la salud, la enfermedad, la espiritualidad y, más aún, la naturaleza humana(5).

Paralelamente, la propagación del yagé ha traído problemas que desvirtúan su ethos original y actúan en detrimento de su enriquecimiento intercultural, pues en su popularización ha quedado atravesado por un campo de relaciones de dominación sujetas a la lógica de mercado vigente, lo que exige tomar una postura política sobre su expansión cultural sin desvirtuar el marco conceptual de espiritualidad y ritualización del que emana ${ }^{(6)}$. Este artículo explora la incorporación del ritual del yagé en occidente, entendiendo su contexto, así como los retos y posibilidades que tiene como alternativa epistemológica y médica.

\section{Materiales y métodos}

El presente artículo se basó en la búsqueda de documentos relacionados en la base de datos electrónicos Web of Science (WoS) donde se utilizó la palabra clave: Ayahuasca. Se consideró que la palabra clave de la búsqueda fuera "ayahuasca», por ser el término más concurrido mundialmente para referirse al brebaje vegetal que el que el término «yagé». Los idiomas considerados fueron: inglés, portugués y español. Se tomaron en cuenta todos los artículos encontrados relacionados con el tema, tanto reseñas como estudios completos.

Se recuperó más de 40 documentos considerados potenciales que se incluyeron como referencias del artículo. Se trataron las diferentes perspectivas disciplinares encontradas sobre el brebaje yagé (neurociencias, biomédicas, psicológicas, antropológicas, filosóficas y sociales). La información recopilada fue revisada en su totalidad y debatida en un seminario de investigación realizado en colectivo por los autores del presente artículo, a partir de su formación profesional (filosofía, sociología, psicología, psicoanálisis, estudios latinoamericanos, historia y epistemología). En dicho seminario, se analizaron los contenidos, conceptos y categorías que permitieron estructurar el artículo, incorporar elementos de discusión en el documento y delimitar líneas de investigación para proyectos posteriores.

\section{Resultados}

Los resultados se presentan en tres secciones principales: la primera explica el contexto de la incorporación del yagé en occidente, la segunda se enfoca en la crisis de occidente desde la medicina y los efectos de conocimiento que esto ocasiona y en la tercera parte se analiza el problema mercantil de la incorporación del yagé en occidente. Por último, se discute la alternativa del trabajo espiritual como otra práctica más allá de la medicina moderna.

\section{Incorporación del yagé en Occidente}

En medio de la crisis de occidente, sintetizada en un fuerte deterioro ambiental, acumulación de capital y guerra, aparece el yagé como una alternativa de sanación física y espiritual tanto a nivel individual como colectivo, dando pauta a la restitución de las 
relaciones humanas y la relación con el entorno. Uno de los distintivos del yagé es su práctica, pues no se trata sólo de un brebaje sino de un consumo ritualizado que posibilita que sujetos pertenecientes a cualquier cultura queden atravesados por una experiencia de sanación espiritual, entendiéndola como el trabajo de problemas actuales como arcaicos a nivel de la humanidad y personal(5).

Por occidente se entiende la civilización moderna capitalista, donde América Latina como región es parte fundante desde su posición colonial(7). En este sentido, el yagé -ubicado en la Amazonía sudamericana- se integra al occidente mediante el mestizaje de la práctica chamánica $\mathrm{y}$, más en específico, con la salida de la selva del ritual del yagé(1). Este proceso de integración es producto de una crisis sistémica, reflejada en los cuerpos de quienes la representan ${ }^{(8)}$ y ligada a temáticas como el antropocentrismo(9), el post-humanismo(10) o el postcolonialismo(2). Más allá de trabajar a detalle algún acercamiento contemporáneo, se revisó el contexto de integración del yagé al occidente y algunas posibilidades médicas, epistemológicas y económicas que se ponen en juego ante la crisis señalada.

El yagé o la ayahuasca consiste en una decocción de dos plantas: Psychotria viridis y Banisteriopsis caapi. Esta segunda contiene alcaloides Beta-carbolinas que son inhibidoras de la mono-aminooxidasa, lo que permite que la dimetiltriptamina (DMT) pueda ser absorbida y distribuida a través del flujo sanguíneo(11). Es un brebaje de origen indígena, conocido con una diversidad de nombres: natema, yagé, nepe, kahi, caapi, nixi pae, shori, kamarapi, cipó, daime, entre otros(12). Ayahuasca es el nombre más utilizado, de origen quechua, que deriva del aya -alma o espíritu- y huasca -liana o cuerda- es decir, se trata de la liana del alma o la soga de los muertos(13). En este documento se le llama yagé, nombre más utilizado en Putumayo, Colombia.

Los movimientos contraculturales de los años sesenta dieron origen a la investigación médica de ciertas sustancias psicoactivas y de sus posibles beneficios en la psique, acompañada de una ideología ecologista globalizada que defendía los derechos étnicos y los movimientos indígenas(14). Esta incorporación inicial trajo una especie de polifonía del chamanismo, algo entre espiritualidad, terapia, conocimiento ecológico y emblema político, tanto de grupos locales que buscaban visibilidad como de grupos occidentales ilustrados en búsqueda de nuevos valores y experiencias sensoriales exóticas(6).

Sin embargo, en esta primera incorporación del yagé a occidente también surgió el temor de que estas plantas consideradas sagradas por los pueblos indios fueran alucinógenos peligrosos, lo que tuvo como consecuencia la creación de políticas públicas que buscaban su desprestigio y prohibición(15). Así surgieron múltiples investigaciones científicas que trataban a las plantas y demás seres de poder como dañinos, donde asumían que eran una moda recreativa, acentuando la mirada en sus abusos, este tipo de investigación -por demás vigente- pone el énfasis en la patología y se centra en los casos de intoxicación(14).

No obstante, pese a que el yagé inicialmente se incorporó a Occidente como una droga -categoría moral que obedece más a factores políticos de control y relaciones de poder que a los principios activos de las sustancias así catalogadas-(16). También dio lugar a otro tipo de investigaciones que comenzaron a dar cuenta del potencial sanador de estas prácticas chamánicas y de la crisis en sentido amplio que el paradigma occidental presenta; investigaciones que ubican los rituales de ayahuasca como experiencias con una función de limpieza psíquica y corporal, dando pauta a la introspección y elaboración de montos catárticos(5).

En la investigación sobre los rituales de yagé llama la atención que, si bien los indígenas de los diferentes países amazónicos han guardado y pulido el conocimiento ancestral de los rituales con la «medicina» o «ciencia» del yagé, el mestizaje también ha jugado un papel importante, no sólo por el fenómeno contemporáneo de la crisis y enfermedad moderna, sino también desde una apropiación cultural(8). Ejemplo de ello es el Santo Daime (daime es el nombre que se le da en Brasil a la preparación vegetal), una religión mestiza al noreste del país, en el estado de Acre, creada a partir del ritual del yagé con alrededor de cuatro mil miembros(17). La religión fue fundada en la década de los treinta y en las últimas dos décadas se ha extendido por diversos países de Europa(18). Es importante rescatar que el caso del Santo Daime es una religión mestiza reconocida por el Estado con un modelo comunitario en torno al daime que va desde la educación hasta la elaboración de política pública(3). 
Otro tipo de mestizaje digno de mención es el que ha tenido lugar en el centro de Takiwasi, en Perú, fundado en 1992, donde presenciamos una escena conformada por curanderos, médicos, psicólogos y terapeutas que en conjunto rescatan el poder curativo del racionalismo occidental mezclado con prácticas chamánicas y terapias tradicionales, utilizando plantas, dietas, aislamientos con la naturaleza, vida comunitaria, psicoterapia y ayahuasca(19). Las divergencias entre las apropiaciones mestizas del Santo Daime y de Takiwasi, en términos de movimiento religioso-profético -el primero- y de centro terapéutico orientado al fortalecimiento de políticas de salud interculturales -el segundo-, encuentran convergencia en la relación que tiene la sanación ritual con la terapéutica, donde la intervención mestiza inicia una occidentalización también epistemológica del yagé, o al menos sugiere su viabilidad(20). Esta convergencia mestiza entre ritual y terapéutica es el contexto para la emergencia de las ceremonias urbanas del yagé o ayahuasca, brebaje que lleva consumiéndose milenariamente por distintos grupos indígenas amazónicos pero que no había despertado el interés occidental hasta el siglo pasado, escapando por primera vez al uso exclusivo indígena no occidental(5).

En la actualidad, existen investigaciones que reconocen el potencial sanador del brebaje entendido como una limpieza profunda en múltiples dimensiones (cuerpo, mente, emociones, espíritu). Dichas investigaciones no sólo se centran en los efectos puntuales del brebaje, sino que apelan a una experiencia mística que reestructura la percepción de la enfermedad, más que apelar a su disolución o extirpación tal como lo hace la noción occidental de «curación»(19). Esta diferenciación conceptual en torno al concepto de salud y enfermedad pone en evidencia los límites de la medicina moderna anterior y la necesidad apremiante de una pauta de comprensión transdisciplinar que aborde la complejidad del saber chamánico y las propiedades etnomedicinales del yagé desde un lugar bio-psicoantropo-social, basado en un diálogo subjetivoobjetivo(21).

Si bien de inicio las visiones del yagé fueron consideradas como una manifestación irrelevante de ontología paranormal, que no podía ser entendida desde la representación moderna, sino que pertenecía al orden de la ficción, la fantasía y de la magia, y que por tanto se contraponía a las nociones del conocimiento científico hegemónico(4), cada vez hay más estudios de corte sociocultural que, rescatando lo nativo, buscan dar cuenta del aporte simbólico del chamanismo y de la religión en la construcción integral de identidades individuales y colectivas que puedan hacer frente a los estados de enfermedad(22), así como estudios cientificistas y biomédicos que utilizan la medición y la metodología de las ciencias duras para intentar arrojar luz sobre los alcances y las formas en las que el yagé se presenta como una alternativa de sanación(3).

Esta escena ha generado un debate inicial, desde diferentes tópicas y problemáticas, en torno a la religiosidad, a lo espiritual, lo terapéutico y lo recreacional, lo que ha traído consigo discusiones situadas en las fajas epistemológicas de la antropología, la neurología, las ciencias biomédicas, la psicología, la psiquiatría y el derecho, dando paso a nuevas entidades complejas y nuevos planteamientos ontológico-epistemológicos que evidencian los límites del conocimiento especializado dual que tradicionalmente ha separado a la cultura de la naturaleza, a la materialidad de la espiritualidad y a la mente del cuerpo(23).

Así, poco a poco, la crisis epistemológica que desencadena el yagé ha ido atrapando el interés de más consumidores urbanos y con ello de investigadores que han puesto atención en la dimensión corporal, anímica, sensorial y cognitiva de sus efectos terapéuticos; dimensiones de lo humano que complejizan y complementan el debate en torno a la enfermedad y al paradigma alópata de salud(11) pues, independientemente del lugar de verdad que se le dé a las visiones, sea desde un enfoque psicologista o desde un enfoque espiritual o transcendental -que autores como Shannon rechazan pero resultan centrales en el saber chamánico-(21), la visión que brinda el brebaje de la ayahuasca contribuye a la resolución de conflictos del individuo, no sólo desde un punto de vista neurocerebral(24) sino también simbólico(22).

Por este motivo, lo que inicialmente era considerado como un brebaje meramente psicodélico ha ido adquiriendo mayor atención mediática e interés público al colocarse como una alternativa -aunque a mucho menor escala- de la medicina psiquiátrica occidental, y en este sentido, ha comenzado a buscar legitimidad en ciencias biomédicas, en la investigación y sobre todo como medicina, con el 
agregado de que el yagé, a diferencia de la medicina psiquiátrica, no genera dependencia, no exige un consumo sistemático ni tiene efectos secundarios nocivos para la salud.

Así, el ritual del yagé como potencial terapéutico, a partir de tradiciones originarias no occidentales, nos invita a ir más allá de la mirada médica y la psiquiatría moderna(18), rescatando el factor del ritual como una sanación que, antes que una extirpación del «mal»en el cuerpo, pasa por una integración de campos aparentemente dispares, algo igualmente aplicable a la persona como al propio Occidente en tanto cultura y sistema; más que una extirpación, plasticidad(23).

\section{Crisis de Occidente y conocimiento médico}

La medicina occidental parte del presupuesto de que el punto de partida y el punto de llegada es la salud, concebida como un estado constante, en donde la enfermedad llega como una anomalía concreta que debe ser exterminada. Esta concepción ubica a la enfermedad como ajena al sujeto, como un mal no muy distinto al de una posesión. El bienestar se asume como un estado en permanente plenitud que le es «dado» al individuo, lo que lo exime de trabajar en su salud como una construcción oscilante que se apega a los fenómenos vitales de su propio cuerpo y de sus procesos vivenciales ${ }^{(8)}$.

La medicalización alópata replica esa misma lógica moderna: los medicamentos pretenden disolver la enfermedad sin participación activa del sujeto o comprensión alguna de qué la detonó, pues si bien se habla de hábitos de alimentación o de estilos de vida poco saludables, se obvia la apropiación del sujeto a la enfermedad misma, derivada de interpretaciones experienciales y de nociones del mundo(1).

La sanación por medio del yagé, en cambio, exige la identificación espiritual del sujeto con su enfermedad y la reapropiación de la misma desde un renacimiento ontológico: el remedio le brinda al sujeto conocimiento sobre su historia personal y sobre la interpretación que ha hecho del mundo a partir de sus emociones primarias consolidadas en sus primeros años y en la base de su percepción familiar del mundo, mismas que a menudo merman su desarrollo, su expansión y su salud(10). Paralelamente, el involucramiento físico del tomador de yagé en su sanación es mucho mayor que el del paciente de la medicina alópata, pues el efecto del brebaje dura varias horas, es en un contexto ritual que dura generalmente toda la noche e incluye purga (vómito y diarrea)(20).

Además, el yagé le permite al individuo reconectar con su entorno, lo que genera nuevas formas de relación con la naturaleza y entre los individuo(25). En esa medida, el yagé es también un llamado a la toma de responsabilidad sobre los propios procesos espirituales, corporales, sociales y psicológicos. Al acceder a una forma de sanación distinta, también se accede a una noción de salud, de bienestar y de integridad biopsicosocial distinta: se diluye la construcción de la enfermedad porque se diluyen también los conceptos que la sostienen(4).

Desde ese encuadre ritual, no es accidental que con frecuencia los consumidores de yagé relaten episodios pesadillescos cuando se encuentran bajo sus efectos, pues en esta identificación con la propia enfermedad se da un proceso catártico de aceptación y un replanteamiento de paradigma al que el Santo Daime otorga el nombre de «la muerte del ego»(16); es decir, la muerte del núcleo de atribución llamado «yo» que se basa en memorias y bloqueos localizados en el inconsciente a partir de las cuales el sujeto se mimetiza con su enfermedad(18), lo que paradójicamente le imposibilita tomar postura frente a ella y, en esa medida, sólo la padece como si de un agente extraño se tratara.

El yagé en su vertiente mestiza ha sido utilizado para intervenir con enfermedades occidentales en las que la ciencia moderna ha quedado limitada, como son adicciones o farmacodependencia, comportamiento suicida, depresión, fobias, ansiedad, estrés postraumático o cáncer(16). Los estudios donde el yagé es usado con pacientes terminales de cáncer para la ansiedad, nos queda claro cómo la sanación no es algo estrictamente comprometido con la práctica de la curación médica occidental basada en la extirpación, se trata más bien de una sanación espiritual principalmente, de una «inteligencia existencial» (más adelante detallada)(18).

De igual manera, ha sido utilizado para intervención en casos de esquizofrenia, donde se rescata -como ya dijimos- la importancia del ritual supervisado y el control de riesgos en la ingesta oral de DMT con paciente diagnosticados con trastornos psicóticos(26). El caso de la psicosis es por demás interesante: por un lado, se encuentra vigente el debate sobre el riesgo de la psicosis por ayahuasca y su uso para tratar la 
esquizofrenia; por otra parte, se apuesta también por un replanteamiento en el paradigma de la psicopatología occidental moderna, brindándole nuevos asideros simbólicos -por tanto, nuevas fronteras de salud- al paciente psicótico(27). Actualmente la escena inicial está en congresos, comunidades terapéuticas y la propia sociedad, discutiendo los posibles beneficios del yagé. Por el momento las investigaciones no son concluyentes, por lo que se puede pasar a una etapa de mayores resultados y debate al respecto(1).

La sanación o limpieza con yagé a nivel somático consiste inicialmente en depurar el organismo. Por otro lado, se habla de una reestructuración cognitiva que implica nuevos modos de resolver problemas, inaugurando aperturas creativas y revalorizando comportamientos(19). Lo emocional está ligado a la conexión con motivaciones, apegos, bloqueos previos, y lo espiritual es la parte mística de la experiencia, que conlleva una reconexión con la naturaleza y el ambiente, la música y la danza(28). No podemos afirmar que una persona con cualquier enfermedad o trastorno quedará sanada, en la medida que no haga un trabajo espiritual cuando participa en el ritual; sin embargo, existen reportes en participantes que en mayor o menor medida reportan cambios(19).

El mestizaje del ritual de sanación espiritual involucra la participación de distintas disciplinas del conocimiento tradicional, científico, terapéutico, jurídico, pedagógico, filosófico y artístico, lo que crea un puente transdiciplinario que hace dialogar a áreas de conocimiento que usualmente no comparten objetos de estudio, ofreciendo puntos de convergencia emergente(6). El nuevo interés occidental le exige ponderar aproximaciones al problema del ser humano previamente descartadas en relación a su salud, y también, por su potencial en la industria del conocimiento y las universidades, ya que pone en juego elementos como registros de propiedad intelectual o de biopiratería(2). Este interés tiene un impacto inicial en el área del conocimiento científico y filosófico al volver a poner el saber chamánico sobre la discusión, provocando cada vez más interés de parte de Occidente en el conocimiento indígena, como se puede constatar cuando se ve la oferta de conferencias sobre chamanismo y debates epistemológicos, una oferta que antes hubiese sido irrelevante o considerada digna de enfermedad mental(16).
La crisis de Occidente está ahí donde el saber moderno se cae o se aprecian sus límites, desde la dualidad cuerpo-mente ya mencionada, hasta el reduccionismo material que no contempla la dimensión espiritual. En ese sentido, el yagé pone a operar un desorden epistemológico que, como tal, reestructura y ofrece sanación(1). La complejidad transdisciplinar del yagé va desde la química hasta la etnografía, estableciendo correlaciones entre funciones cognitivas y estudios experimentales, además de la llamada etnomedicina, campo en el que podemos ubicar este tipo de enfoques que recuperan el chamanismo presente en los indígenas del Amazonas(21). Es importante señalar que la etnomedicina ya forma parte de un proceso de mestizaje o incorporación del ritual indígena(3).

La apertura a ese otro tipo de conocimiento, reconocido desde la crisis de Occidente como un pensamiento transdisciplinar desde nuevos diálogos epistemológicos, ha sido llamado «inteligencia existencial»(16). Una apertura de las plantas maestras, una ampliación de saberes y de la vida cotidiana del sujeto y una apuesta por la diversidad, la complejidad, las prácticas de cuidado y las nuevas capacidades poéticas e imaginarias(28). El yagé como tecnología opera como un microscopio o telescopio que ofrece visiones que de otra forma no accederíamos; los rituales enteogénicos traen consigo avances potenciales en el plano psicofísico y existencial que permiten que ciertas crisis espirituales se resuelvan como parte del ritual mismo(18).

\section{La falsa ruptura: charlatanería e interés mercantil}

El yagé o ayahuasca se ha convertido en las últimas décadas en un fenómeno sociológico postcolonial que se presenta como un ritual que sana a nivel somático, cognitivo, emocional y espiritual, una etnomedicina que surge como un híbrido entre lo tradicional y lo moderno (2). Dentro de la incorporación del yagé como medio de sanación para la crisis moderna se pueden señalar diferentes intereses y rumbos, algunos de ellos ilegítimos ya sea por sus fundamentos o por sus motivaciones: ya hemos mencionado, por ejemplo, la postura que mira al yagé como una droga que se estudia desde categorías patológicas y los abusos en su uso, obviando el contexto ritual que lo soporta(11); asimismo, existe otra postura que no pretende hacer grandes cambios y sólo busca producir ganancia económica más que sanación(6). 
Entre más popular se vuelve, más grupos desvirtúan su ethos original, en detrimento de su cultivo y de su enriquecimiento transdisciplinario e intercultural(29). El saber-poder del que dispone el brebaje del yagé se encuentra atravesado por un campo de relaciones de dominación que no escapan a la lógica de mercado vigente, lo que exige tomar una postura política sobre su expansión cultural y determinar los parámetros bajo los cuales una ceremonia urbana de yagé puede tener lugar sin desvirtuar el marco conceptual de espiritualidad y ritualización del que emana, al ser éste uno de los factores principales de la sanación que ofrece. En esa medida, el estudio de la entrada de yagé a Occidente también requiere analizar los movimientos en los que opera según la valorización mercantil para poder desmarcarse y crear una ética que lo sustente en sus nuevas circunstancias, tomando en cuenta las discusiones políticas derivadas de la expansión internacional de la práctica ceremonial amazónica(8).

Los orígenes remotos de la bebida vegetal descienden de miles de años con gran cantidad de abrevaderos mitológicos en por lo menos setenta y dos pueblos indígenas diferentes esparcidos en la selva amazónica de Brasil, Colombia, Perú, Venezuela, Bolivia y Ecuador, de tal manera que desde sus comienzos ha sido parte de un encuentro de tipo transcultural(4). Al empezar a ser concebido como un objeto de colonización, el conocimiento milenario del yagé fue introducido en campos de disputa en los que se empezó a concebir como un producto rentable, con gran potencial farmacológico(30) y sujeto a ser mercantilizado para extraer plusvalía, dada su condición de posibilitador en procesos cognitivos y terapéuticos(11).

No han faltado los intentos de depredación directa hacia las plantas que componen el brebaje por parte de extranjeros interesados en extraer usufructo a partir del despojo, patentar y adquirir la propiedad intelectual de la misma. Tampoco han faltado los intentos de explotación al especialista indígena, que suele encontrarse en desventaja ante los intermediarios nacionales e internacionales que abusan de su disposición para trabajar su oficio, así como usurpadores sin ningún tipo de preparación profesional que irresponsablemente se han aventurado a buscar beneficio individual(29). Esta burda apropiación colonial oculta y niega el contexto socio-histórico de donde surge la práctica y la tradición( ${ }^{(8)}$.
Las diferentes tácticas de mercantilización colocan al yagé en una situación sumamente delicada, pues el enfoque exclusivamente mercantilista trivializa el proceso de sanación y muchas veces no provee las condiciones ceremoniales de contención, encuadre y acompañamiento que la misma necesita. Si bien la lógica de mercado se desprende de un proceso de producción histórica y, de cierta manera, consolida el éxito del brebaje, garantizando que más personas de origen no-indígena lo consuman, la dimensión ética del remedio va más allá de una mirada únicamente individualista; por el contrario, se esfuerza por la creación de nuevas formas colectivas de armonía, aunque no necesariamente homogéneas ni exentas de contradicciones ${ }^{(25)}$.

Es necesario destacar que suplantar la posición del especialista, es decir, prescindir de la mediación de un experto con formación chamánica, no sólo es funcional para los agentes externos interesados sino también dentro de las mismas culturas indígenas existen contradicciones, lo que lleva a considerar formas alternativas de regulación, principalmente en el seno de organizaciones comunitarias autónomas como en los marcos legislativos gubernamentales. De igual modo, en las ciudades se comienzan los debates sobre los beneficios sociales de los rituales de yagé(1).

En Colombia, por ejemplo, los llamados taitas -brujos o chamanes-, en 1999 hicieron la Unión de Médicos Indígenas Yageceros de la Amazonia Colombiana, poniendo el acento en la defensa del territorio y sus plantas(6). Esta misma inquietud ha ocupado a especialistas que han tratado de formular e impulsar el intercambio de saberes y, en esa medida, regular con el debido rigor el uso de enteógenos en contextos occidentales, principalmente europeos. Esta expansión hace que resulte inevitable disputar y concertar los diferentes intereses en juego sobre los ámbitos jurídico-políticos correspondientes a cada región, en especial cuando se trata de territorios ancestrales habitados por pueblos originarios ${ }^{(10) .}$

Sin embargo, lo anterior también podría colocarse en clave colonial; es decir, al querer normar con marcos teóricos occidentales, se termina por desconocer o menospreciar los saberes tradicionales y desechar su propuesta epistémica según la validación del poder biomédico hegemónico alópata. En la última década, a medida que los pueblos indígenas han ido cediendo a las relaciones capitalistas, la circulación internacional de la práctica del yagé ha alcanzado 
cada vez mayor auge, igual que la nacional -es decir, en el interior de los países que albergan el yagé-, pues en dichos países el remedio se ha ido propagando de las zonas rurales hacia los centros urbanos(8).

El riesgo de la incorporación del yagé en Occidente es que la preparación, concebida sagrada para los pueblos indígenas, ha pasado a ocupar un lugar de mercancía dentro del libre mercado como una droga capaz de proporcionar dinero o poder(1). Al mismo tiempo, produce un interés superficial por lo espiritual y por los saberes indígenas locales que, sin una inmersión profunda en sus principios, termina por trivializar el saber tradicional chamánico, convirtiéndolo en un chamanismo improvisado que pondera o totaliza su misión en la ganancia económica(2).

El auge del yagé tiene un éxito inicial en el orden de la promesa, no tiene un pasaje como medicina popular y a la fecha ha sido adoptado únicamente por las clases altas y profesionales urbanas. En este sentido, la promesa del yagé se articula más como una alternativa existencial, una terapéutica, o neochamanismo que contrasta con el chamanismo tradicional y desvirtúa el significado verdadero del ritual. Al trivializarse el saber chamánico, incluso por los mismos chamanes que al salir de su lugar de origen y ver beneficio económico descuidan los principios de su oficio, el yagé pierde su condición de medicina sagrada para devenir en una mera mercancía(1).

La metonimia del estado de bienestar alternativo con el ritual del yagé ha traído nuevas complejidades que es importante analizar: por un lado, los rituales se han urbanizado y salido del contexto tradicional, con ello se han simplificado y estandarizado, sobre todo, se ha incorporado al Occidente ampliando la oferta del mercado(1). Por otro lado, el chamán o taita ha perdido el centro en el ritual, dejando el lugar cada vez al brebaje en sí y a la entrada de nuevos actores sociales en la dirección del ritual(8).

Es muy complejo dar cuenta de la pérdida de centro del chamán. Por un lado, saltan los desvíos y complicaciones de su práctica fuera de su lugar originario o con personas ajenas a su contexto tradicional. Asimismo, la amplificación de la oferta ha hecho que el ritual vaya perdiendo seriedad y se mecanice, dejando en el centro a la mercantilización(29). Por otro lado, la pérdida de la centralidad del chamán permite que la bebida milenaria pase a tomar el lugar central y el ritual en sí mismo cobre mayor peso en ausencia del chaman indígena, lo que pone en relieve la relación entre chamanismo «ayahuasquero» e indigenismo político, donde el indígena es pensado como la encarnación antropomórfica del ideal ecológico y se reivindican las minorías étnicas dentro de un ecologismo globalizado, estableciendo una relación clientechaman ${ }^{(6)}$.

\section{Discusión}

\section{La metonimia del yagé y el trabajo espiritual}

Hemos visto la crisis occidental enfrentada primero desde un rechazo de la práctica ceremonial amazónica y posteriormente desde una supuesta incorporación o incluso falsa ruptura que se traduce como turismo eminentemente recreativo, donde el yagé se inserta al mercado como mercancía mientras se va haciendo de lado tanto el saber cómo los maestros de tradición(6). Tendríamos una tercera posibilidad de enfrentar la crisis: salir de los parámetros del conocimiento médico moderno de salud para encaminarnos hacia una concepción enfocada en el trabajo espiritual; es decir, otro modelo de salud con métodos y fines distintos de sanación, como ocurre en los sacramentos de las religiones que hacen uso del yagé donde su contexto ceremonial, así como su propio marco simbólico, otorga mayor posibilidad de optimizar y reducir los riesgos de reacciones adversas a las experiencias con sustancias psicoactivas ${ }^{(19)}$.

En este contexto, el estudio del yagé ha adquirido auge como posibilitador de sanación desde un marco conceptual que diverge del conocimiento occidental e incluye el conocimiento de las tradiciones originarias, con una implicación de orden social, político, económico, ideológico y conceptual. Hoy en día, con el antecedente de abuso recreativo del movimiento psicodélico de los años sesentas, el yagé resurge con potencia en las áreas de la salud como preparado de plantas sagradas, pero ahora resignificado como enteógeno, ya que se utiliza principalmente por su potencialidad terapéutica(31). En este orden de ideas, podemos afirmar que el yagé dejó de ser considerada una droga en sentido occidental del término -con toda su carga peyorativa- y comenzó a ser un enteógeno, una sustancia de origen vegetal revestida de sentido sagrado que propicia una sanación a nivel espiritual(1). 
Con el yagé como medicina sagrada asistimos también al reconocimiento y traspaso de las fronteras culturales que encubrían el conocimiento de las tradiciones originarias por la dominación colonial de Occidente(21). Además, con la consideración del yagé como enteógeno, se da pie a que el saber de los maestros originarios se convierta en una categoría de convergencia entre técnicas psicoterapéuticas de distinto alcance, siendo la más destacada la psicología transpersonal pero sin descartar otras aportaciones de saberes adivinatorios, tales como el tarot, runas, mediumnismo, hasta proyectos dirigidos al cuidado ambiental y de impulso a los derechos de los pueblos indígenas amazónicos(6).

El público occidental «ayahuasquero» que busca sanación desde el enfoque espiritual, se localiza principalmente en las ciudades de Europa, Estados Unidos de América y Latinoamérica, en grupos sociales de alto poder adquisitivo, generalmente profesionistas liberales pertenecientes al ámbito intelectual o artístico, empresarios multinacionales que demandan terapias alternativas(6). Hasta aquí, el yagé sería una convergencia psicoterapéutica de todo tipo, con un público urbano, clase media, ilustrado, liberal o empresarial(8).

La difusión mundial de la práctica ceremonial amazónica del yagé nos da cuenta de su gran capacidad de adaptación, no sólo para trabajar en problemas de salud desde un nivel espiritual, sino también, dada su plasticidad, le permite ser accesible a lugares geográficamente alejados y culturalmente diversos, sin necesariamente estar inmersos en especificidades del contexto de donde proviene(20). Esta plasticidad está intrínsecamente relacionada con concepciones básicas del conocimiento tradicional originario que, al encontrarse más próximo a la tradición oral y a la narrativa simbólica, permite una descentralización de la razón objetiva y de la mente como agente aislado que actúa sólo en relación a lo fenoménico(23).

Las dificultades con las que se enfrenta el saber científico para tratar la complejidad de lo que ocurre en un ritual de yagé dan cuenta de la crisis epistemológica de Occidente ${ }^{(8)}$, y la sanación que el consumo de este brebaje ofrece a personas que no han encontrado solución a sus enfermedades tratándose con medicina occidental, sugiere las limitaciones de ésta última. Asistimos así a los límites epistemológicos modernos y al necesario llamado a trascenderlos, abriendo la posibilidad de un nuevo diálogo intercultural desde campos diversos del saber; es decir, desde una aproximación transdisciplinaria, ya no sólo entre las disciplinas cultivadas en Occidente (ciencia, arte, filosofía) sino con saberes del conocimiento tradicional originario, que implican nuevas lógicas $y$ marcos conceptuales(16).

Así pues, se habla de las plantas de poder como herramientas que ayudan en el trabajo espiritual desde diferentes ángulos complementarios, desde el campo biológico (los efectos de las sustancias activas en los procesos vitales), el campo psicológico (la emotividad $y$ el sentido personal de buscar introspección), el campo socio-cultural (relaciones sociales del contexto histórico determinado) y el campo del espacio de ritualización (el ambiente construido con la vibración de la música, danza y el procedimiento idiosincrático que lo acompaña)(19). Esta conjunción de elementos exige un replanteamiento en el abordaje del concepto occidental de salud, comúnmente considerado sólo desde su dimensión biológica. El trabajo espiritual con el brebaje del yagé atraviesa todos los campos anteriores, tanto en un nivel primario (físicoquímico-biológico) como en un nivel secundario (psico-social y socio-cultural)(11).

La instancia primaria o físico-química se caracteriza principalmente por sus efectos purgativos (evacuaciones que pueden ser desde el estómago como del intestino). Cabe señalar que dentro de la concepción de las tradiciones amazónicas los procesos corporales de purga son una forma de limpieza en el cuerpo requerida para el mismo proceso de sanación del sujeto, de manera que la depuración de lo que el cuerpo expulsa no es exclusivamente biológico sino también espiritual. Además de la purga, se producen efectos psíquicos que impactan en la química cerebral de los neurotransmisores ${ }^{(3)}$. En esta dimensión primaria se habla asimismo de una función enteroceptiva; es decir, de la percepción del estado de los órganos internos, semejante a las técnicas alcanzadas la mediante meditación, donde el sujeto toma conciencia de sus procesos fisiológicos, lo que posibilita modificaciones perceptuales, sensoriales y cognitivas que le permiten replantear su relación con su propio cuerpo y su entorno(22). Dicho de otro modo, el campo primario en el que el efecto purgativo tiene lugar es, al mismo tiempo, posibilitador de cambios a 
nivel psicológico, pues ofrece una percepción ampliada sobre el entorno y sobre los propios procesos fisiológicos, permitiendo nuevas elaboraciones cognitivas en el sujeto(20).

La instancia secundaria o sociocultural se encuentra estrechamente ligada con la primaria, pero contempla asimismo todos los elementos que incluyen la ritualización, tales como los efectos sonoros que se articulan en ella y sus consecuencias en la elaboración subjetiva de la experiencia y, por tanto, en la sanación que de ella emana(32). Lo secundario de entrada tiene que ver con las visiones o la "pinta" -término utilizado en la cultura cofán-, que quizá sea la particularidad más específica de la experiencia del yagé, se le denominan visiones a la información a la que accede el individuo bajo el efecto del yagé, generalmente de forma visual a ojos cerrados, a menudo descritas como fantásticas o fabulosas(33). Sin embargo, en esa misma categoría se incluyen las experiencias que, sin ser visuales -pueden ser emocionales, sonoras o conceptuales- son vividas no como un mero producto de la propia imaginería, sino como información otorgada por el brebaje, al que se le atribuye un saber propio. También, aunque no tan frecuentemente, se registran visiones a plena vista, donde el individuo visualiza otra realidad con contenidos de aprendizaje y de sentires trascendentales(34). De igual manera, el yagé posibilita experiencias en las que la sensibilidad se ve incrementada, así como la intuición primitiva animal y la empatía y empatía hacia todo lo vivo y en especial, hacia los otros participantes de la experiencia colectiva( ${ }^{(4)}$. Es importante mencionar la pulcritud de la sanación con el yagé en su conexión entre lo sensitivo con lo espiritual, mediante una disolución racional con lecciones que llegan de manera intuitiva(35).

Los tomadores de yagé señalan que el remedio trabaja por medio del estado de éxtasis al que nombran "vuelo del trance", que se detalla como un transición entre los espacios elevados y luminosos con los subterráneos oscuros y putrefactos; estadios que son leídos por los pacientes como psicológicos representaciones de la interioridad del sujeto- pero que, de acuerdo a la cosmovisión originaria, tienen una realidad espiritual independiente, lo que da cuenta de la integralidad con la que el conocimiento tradicional contempla la salud del ser humano y su entorno, en equilibrio con lo emocional y lo corporal(1). Esta concepción de salud tiene como particularidad integrar la dimensión espiritual en la sanación del sujeto y buscar su armonización desde esa integralidad bio-psico-espiritual a través de una purificación sin precedente capaz de conectar al individuo con una dimensión sagrada única(8).

Es importante asimismo especificar que la práctica ceremonial amazónica tiene un formato de tipo pedagógico, lo que la acerca más a una escuela que a una psicoterapéutica, aunque el trabajo espiritual con el yagé persigue la salud, no es la terapéutica su principal método de intervención, sino que la salud llega como resultado del procesamiento de los aprendizajes otorgados. De ahí la vindicación de los efectos purgativos y visionarios, el imperioso paso de la instancia primaria a la secundaria, donde se obtiene un saber introspectivo que auxilia al sujeto en el profundo replanteamiento del mundo que lo rodea(35). Por ello el énfasis en la ritualización para el trabajo espiritual con yagé, más que por la figura del linaje o chamánica como tal, por la capacidad metonímica con la que el yagé actúa(6).

El trabajo espiritual podría ser definido, en consecuencia, como una inmersión en la dimensión sagrada, distinta del vivir cotidiano que en el estado de conciencia que otorga el brebaje se percibe lejano e irrisorio, ofreciendo con ello un cambio paradigmático y axiológico en la forma de habitar el mundo, un saber trascendental que le permite al sujeto replantear la conexión con el todo y revisar su código ético en lo personal, moral, social, espiritual, ancestral, animal, vegetal y seres sobrenaturales(34). Mediante el ritual -compuesto por la sonorización, el estado meditativo y el movimiento corporal-, el cuerpo entra en trabajo espiritual y recibe humildad $\mathrm{y}$ amor al otro como resultado; se incorporan nuevos elementos simbólicos y conceptuales que le permite a la conciencia rebasar sus límites previos tanto a nivel perceptual, como a nivel empático y creativo(31). Con el trabajo espiritual vemos algo nuevo que se aleja de la terapéutica, y se liga al ritual, al nuevo conocimiento de las visiones y la purga, a la danza, a lo ancestral, pues la experiencia supone un desafío para el sujeto al colocarlo en una situación desconocida -donde se revierten y reestructuran procesos integrales-, generando las condiciones para que pueda hacer cambios estructurales en su persona(20).

Hasta aquí, se expuso una revisión sobre la investigación contemporánea del yagé. Inicialmente se explicó el contexto de la crisis de Occidente a nivel 
civilización y el anclaje del ritual del yagé como alternativa, donde la investigación con psicodélicos y la contracultura, por un lado, y por otro, el mestizaje que inicia con la salida de la selva del ritual del yagé, son los dos momentos decisivos en la integración del yagé al mundo occidental. Hemos visto que la categoría de «crisis» utilizada para referirnos a los problemas contemporáneos del mundo occidental se puede ver reflejada tanto a nivel somático como en relación a los problemas epistemológicos $\mathrm{y}$ económicos de la modernidad(8).

Posteriormente, se planteó el ritual del yagé como alternativa a los límites de la medicina moderna, el cual, dadas sus características, abre un nuevo diálogo epistemológico con enfoques contrapuestos que van de la psiquiatría a la transdisciplina(36). Más que asumir sin crítica que el yagé sirve para atender todo problema médico y puede utilizarse sin reservas en trastornos psiquiátricos, el debate nos condujo al cambio de modelos, cuestionando particularmente el modelo de medicina moderna al contraponerlo con las posibilidades del modelo ritual de uso del yagé(1). Sin embargo, es conveniente revisar más referencias respecto de la relación entre yagé y los trastornos psiquiátricos, sobre todo en referencias biomédicas(37).

En este orden de ideas, la investigación sobre el yagé está en un momento inicial, existen postulados sobre sus posibles usos para determinadas enfermedades y trastornos, pero las evidencias en la investigación biomédica no son concluyentes por el momento. En este sentido, la investigación biomédica se ha acercado al abordaje del problema(38). El estado de emergencia de la metodología bioquímica está haciendo posible conocer de modo científico las pretendidas propiedades curativas del yagé(39) produciendo un efecto de apropiación al quedar avaladas por la ciencia médica(14). Esto abre nuevas posibilidades de investigación experimental(39).

Más allá de la variabilidad botánica de la ayahuasca(40) se finalizó reconociendo los usos del yagé. Si bien hay usos más «neutrales» como la purga en la terapéutica amazónica, el yagé presenta un lado problemático en su ejercicio y propagación, tanto en contextos tradicionales(41) como en contextos urbanos, que incluyen problemas de mestizaje y abusos de extranjeros a chamanes indígenas ${ }^{(34)}$. Nosotros analizamos el uso mercantil que tiene el yagé en las ciudades y las implicaciones de una apropiación colonial: dejar de un lado el cuidado del ritual para poner la ganancia por delante o imponer un modelo epistemológico ajeno a la cultura en la que nace ${ }^{(1)}$.

Por último, se analizó el carácter localizado, política, ética y contextualmente del «trabajo espiritual»(16) sin hacer un análisis de la igualación conceptual entre «chamán» y «taita»; es decir, sin colocar en perspectiva las genealogías intelectuales que dieron origen a ambos términos( ${ }^{42)}$. Distinguimos el descentramiento de un chamán en el ritual mestizo del yagé, lo que abre el campo del camino espiritual y nos aleja de una terapéutica como tal. El trabajo espiritual sería una práctica basada en enseñanzas, que van desde purgas hasta visiones, donde se depura el cuerpo a nivel biológico, afectivo y cognitivo(8).

Es necesario discutir con más enfoques contrapuestos, así como dialogar con otros autores para profundizar en las problemáticas detectadas(43) sobre todo en torno al tema de las utilidades del yagé(36), así como de las medidas terapéuticas que aún no cuentan con suficiente evidencia para ser propuestas como efectivas(21).

\section{Conclusiones}

Si bien la actualidad de la práctica ceremonial amazónica se esparce a nivel mundial necesariamente mediante un mestizaje que implica la adaptación hacia contextos principalmente urbanos, en la medida que se ha ido incorporando su uso en las poblaciones occidentales y se han desarrollado propuestas de religiosidad y terapéuticas que consideraron apropiado canalizar las potenciales de sanación del yagé en un trabajo espiritual. Nuestra apuesta en este estudio es identificar cómo el proceso de ritualización produce un efecto metonímico en los sujetos y su entorno a partir de analizar los diferentes usos y aplicaciones del brebaje yagé en Occidente, así como las vicisitudes e intercambios culturales, económicos y políticos que suscitan en los diferentes ámbitos académicos, gubernamentales y en los propios pueblos originarios.

Nos centramos en la adaptación de la práctica ceremonial en espacios urbanos occidentales como elemento metonímico principal. Para ello, exploramos el concepto de "trabajo espiritual" para dar cuenta de la complejidad de la dimensión sagrada y de los procesos de sanación que ocurren en la ritualización de esta preparación vegetal. Así, nos 
acercamos al conocimiento tradicional indígena y lo incorporamos en la discusión desde un modelo transdisciplinar que involucra los campos de la fe, la salud y el conocimiento.

Si bien hay avances importantes desde esas mismas apuestas de apropiación y de adaptación sociocultural de las iglesias y centros terapéuticos que realizan un trabajo espiritual en relación al vislumbramiento de nuevas aplicaciones comunitarias con alcances educativos y de políticas públicas de salud, desde miradas con intenciones interculturales, nuestra aportación radica en propiciar la discusión epistemológica que fundamente ese mestizaje y dé pauta para que la reproducción mundial de la práctica ceremonial amazónica se realice en consonancia con los principios sostenidos por las tradiciones de los pueblos originarios que han cultivado su conocimiento ancestral.

Es en ese sentido que se presentó el primer seminario del colectivo Yágesis, con el fin de proponer un programa de investigación ampliado que contemplara el encuentro con distintos saberes y el campo de conocimiento alrededor del brebaje sagrado vegetal; es decir, un modelo transdiciplinar de medicina enteogénica especializada en el uso y en la adaptación del yagé en la modernidad capitalista mundializada. No obstante las grandes dificultades de emprender un proyecto de esta envergadura, ya sea por la conciliación de las diferentes fronteras disciplinarias, como por las relaciones coloniales que las atraviesan, es la reunión con el saber tradicional indígena, a partir de sus maestros originarios, lo que más se dificulta, pero somos optimistas de que paso a paso podamos establecer diálogos transdiciplinarios. Mientras tanto, nosotros nos abocamos al esfuerzo de revalorizar la ética y formación de la episteme amazónica. Así pues, se abona la posibilidad de abrir nuevas perspectivas de investigación en torno a la metonimia de equilibrio emocional, cognitivo $\mathrm{y}$ bioquímico del trabajo espiritual con el yagé.

\section{Conflicto de intereses}

Los autores declaran que no existen conflictos de intereses.

\section{Referencias}

1. Uribe C. El yajé, el purgatorio y la farándula. Antípoda. 2008;6:113-31.
2. Tupper K. Ayahuasca healing beyond the Amazon: the globalization of a traditional indigenous entheogenic practice. Glob Networks. 2009;9(1):117-136.

3. de Souza PA. Alcaloides e o chá de ayahuasca: uma correlação dos «estados alterados da consciencia» induzido por alucinógenos. Rev Bras Pl Med, Botucatu. 2011;13(3):349-58.

4. Shannon B. The epistemics of ayahuasca visions. Phenom Cogn Sci. 2010;9:263-80.

5. Córdoba, Martha; Vallejo, Álvaro \& Saa J. Fenómenos transferenciales en las tomas rituales urbanas de ayahuasca. Univ y Salud. 2012;1(15):67-77.

6. Losonczy, Anne-Marie \& Mesturini S. La selva viajera. Rutas del chamanismo ayahusaquero entre Europa y América. Reli e Soc Rio Janeiro. 2010;30(2):164-83.

7. Dussel E. Postmodernidad y transmodernidad. Puebla, México: Universidad Iberoamericana; 2002.

8. Caicedo Fernández A. Nuevos chamanismos Nueva Era. Universitas humanística. 2009;(68):15-32.

9. Labate, Beatriz \& Sena W. O uso ritual da ayahuasca. Porto Alegre: Horizontes antropológicos. 2003;9(19):322-30.

10. Mouriès T. ¿Con o sin ancestros? Vigencia de lo ancestral en la Amazonía peruana. Perú Anthropol. 2014;32(32):17-40.

11. Carlini E.A. Plants and the central nervous system. Pharmacol Biochem Behav. 2003;75:501-512.

12. Riba, Jordi; Anderer, Peter; Morte, Adelaida; Urbano, Gloria; Jané, Francesc; Saletu, Bernd; Barbanoj M. Topographic pharmaco-EEG mapping of the effects of the South American psychoactive beverage ayahuasca in healthy volunteers. Br J Clin Pharmacol. 2002;53(6):613-28.

13. Gambelunghe, Cristiana; Aroni, Kyriaki; Rossi, Riccardo; Moretti, Luca; Bacci M. Identification of $\mathrm{N}, \mathrm{N}-$ dimethyltryptamine and beta-carbolines in psychotropic ayahuasca beverage. Biomed Chromatogr. 2008;22(10):1056-9.

14. Cunningham N. Hallucinogenic plants of abuse. Emerg Med Australas. 2008;20:167-174.

15. Labate B. A reinvenção douso da ayahuasca nos centros urbanos. São Paulo Mana. 2005;11(2):593-604.

16. Albuquerque MBB. Saberes da ayahuasca e processos educativos na religião do Santo Daime. Rev.latinoam.cienc.soc.niñez juv. 2012;10(1):351-65.

17. Oliveira I. Um desafio ao respeito e à tolerancia. Rio Janeiro Reli e Soc. 2011;31(2):154-78.

18. Blainey M. Forbidden Therapies: Santo Daime, Ayahuasca, and the Prohibition of Entheogens in Western Society. J Reli Heal. 2015;54:287-302.

19. Guimarães dos Santos R; Carvalho de Moraes C, Holanda A. Ayahuasca e Redução do Uso Abusivo de Psicoativos: Eficácia Terapêutica?. Psicol Teor e Pesqui. 2006;22(3):363-70.

20. Mercante M. A ayahuasca e o tratamento da dependencia. Rio Janeiro Mana. 2013;19(3).

21. Pereira E. Ayahuasca: expansão de usos rituais e de formas de apreensão científica. 0 uso Ritual da ayahuasca. Rev Bras ciencias sociais. 2003;18(52):203-7.

22. Timmermann C. Neurociencias y aplicaciones psicoterapéuticas en el renacimiento de la investigación con psicodélicos. Rev Chil Neuro-Psiquiat. 2014;52(2):93-102.

23. Guzmán Chávez MG. Antropología simétrica y procesos de curación con ayahuasca. Estud Soc. 2014;22(44):283-7.

24. Santillo MF, Liu Y, Ferguson M, Vohra SN, Wiesenfeld PL. Inhibition of monoamine oxidase (MAO) by $\beta$-carbolines and their interactions in live neuronal (PC12) and liver (HuH-7 and MH1C1) cells. Toxicol Vitr. 2014;28(3):403-10. 
25. Carlini E, Rodrigues E, Mendes F, Tabach R, Gianfratti B. Treatment of drug dependence with Brazilian herbal medicines. Rev bras Farm. 2006;16(0):690-695.

26. Gable R. Risk assessment of ritual use of oral dimethyltryptamine (DMT) and harmala alkaloids. Addiction. 2007;101(2):24-34.

27. Jensen S, Olsen A, Pedersen K, Cumming P. Effect of monoamine oxidase inhibition on amphetamine-evoked changes in dopamine receptor availability in the living pig: a dual tracer PET study with [11C] harmine and [11C] raclopride. Synapse. 2006;59(7):427-34.

28. Labate B, Pacheco G. Música brasileña de Ayahuasca. Brasil: Campinas Merc das Let. 2009;

29. Holman C. Surfing for a shaman: analyzing an Ayahuasca website. Ann Tour Res. 2011;38(1):90-109.

30. Salum AP, Rodrigues C, Moura S, Dörr F, Abreu W, Yonamine M. Gas Chromatographic Analysis of Dimethyltryptamine and b-Carboline Alkaloids in Ayahuasca, an Amazonian Psychoactive Plant Beverage. Phytochem Anal. 2009;20:149153.

31. Meres-Costa CM, Cecchetto-Figueiredo M, Santos-Cazenave S. Ayahuasca: Uma abordagem toxicológica do uso ritualístico. Rev Psiq Clín. 2005;32(6):310-8.

32. Jauregui X, Clavo ZM, Jovel E. «Plantas con madre»: plants that teach and guide in the shamanic initiation process in the East-Central. Peruvian Amazon. J Ethnopharmacol. 2011;134(3):739-52.

33. de Araujo D, Ribeiro S, Cecchi G, Carvalho F, Sanchez T, Pinto J, et al. Seeing with the eyes shut: neural basis of enhanced imagery following Ayahuasca ingestion. Hum Brain Mapp. 2012;33(11):2550-60.

34. Melo R. A União do Vegetal e o transe mediúnico no Brasil. Reli e Soc Rio Janeiro. 31(2):130-53.
35. Sobiecki JF. An Account of Healing Depression Using Ayahuasca Plant Teacher Medicine in a Santo Daime Ritual. Indo-Pacific J Phenomenol. 2013;13(1).

36. Mizumoto S, da Silveira D, Ribeiro $P$, Strassman $R$. Hallucinogen Rating Scale (HRS) - Versão brasileira: tradução e adaptação transcultural. São Paulo Rev Psiquiatr clín. 2011;38(6):231-7.

37. Halberstadt A. Recent Advances in the Neuropsychopharmacology of Serotonergic Hallucinogens. Behav Brain Res. 2015;277:99-120.

38. Gaujac A, Ford J, Dempster N, Bittencourt de Andrade J, Brandt S. Investigations into the polymorphic properties of $\mathrm{N}, \mathrm{N}$-dimethyltryptamine by X-ray diffraction and differential scanning calorimetry. Microchem Journal. 2013;110:146-57.

39. Huhn C, Pütz M, Martin N, Dahlenburg R. Determination of tryptamine derivatives in illicit synthetic drugs by capillary electrophoresis and ultraviolet laser-induced fluorescence detection. Artic Electrophor. 2005;26(12):2391-401.

40. Callaway J, McKenna D, Grob C, Brito G, Raymon L, Poland R, et al. Pharmacokinetics of Hoasca alkaloids in healthy humans. Ethnopharmacol. 1999;65(3):243-56.

41. Whitehead N, Wright R. In Darkness and Secrecy: The Anthropology of Assault Sorcery and Witchcraft in Amazonia. EEUU: Duke University Press; 2004.

42. Sidky H. Ethnographic Perspectives on Differentiating Shamans from other Ritual Intercessors. Asian Ethnol. 2010;69(2):213-240.

43. Stanković D, Mehmeti E, Svorc L, Kalcherb K. New electrochemical method for the determination of $\beta$-carboline alkaloids, harmalol and harmine, in human urine samples and in Banisteriopsis caapi. Microchem J. 2015;118:95-110 